\title{
Diagnostic Accuracy of Doppler Ultrasound for Antenatal Detection of Placenta Accreta Spectrum (PAS) Disorders
}

\author{
Sadia Asghar ${ }^{1, ~ *, ~ N a f e e s a ~} \mathrm{Naz}^{2}$ \\ ${ }^{1}$ Department of Obstetrics and Gynecology, Rai Medical College, Sargodha, Pakistan \\ ${ }^{2}$ Department of Obstetrics and Gynecology, Allied Hospital, Faisalabad, Pakistan
}

Email address:

azanayan36@gmail.com (S. Asghar), drnafeesanaaz@gmail.com (N. Naz)

${ }^{*}$ Corresponding author

\section{To cite this article:}

Sadia Asghar, Nafeesa Naz. Diagnostic Accuracy of Doppler Ultrasound for Antenatal Detection of Placenta Accreta Spectrum (PAS)

Disorders. Journal of Gynecology and Obstetrics. Vol. 8, No. 1, 2020, pp. 12-15. doi: 10.11648/j.jgo.20200801.13

Received: November 19, 2019; Accepted: December 19, 2019; Published: January 8, 2020

\begin{abstract}
Morbidly adherent placenta a spectrum of condition characterized by invasion of placenta to implantation site. Antenatal diagnosis of placenta accrete spectrum (PAS) is highly desirable because fetomaternal out comes can be optimized. Diagnosis of PAS are accomplished with Doppler ultrasound. It has shown to reduce the burden of fetomaternal morbidity and mortality. The purpose of current study was to check the diagnostic accuracy of Doppler ultrasound in detection of PAS while carefully eliminating bias by controlling confounders we aimed to check the accuracy of Doppler ultrasound in detection of PAS. A cross sectional validation survey was done to find out the diagnostic accuracy of Doppler ultrasound in detection of PAS. The mean maternal age was $28.23 \pm 4.31$ years. And Mean gestational age was found to be $34.3 \pm 1.82$ weeks. The mean married age was $3.52 \pm 2.39$ years. Parity of patients were found to be between 1-15 years with mean parity of 1.6 \pm 0.92 . Out of 145 patients 3D Doppler ultrasound showed 94 positive cases while per operative findings (Gold standard) showed 90 positive cases. Sensitivity rate was found to be $86.5 \%$, specificity was $90.24 \%$, positive predictive value (PPV) $95.7 \%$ and negative predictive value (NPV) $72.5 \%$ and diagnostic accuracy of $87.6 \%$.
\end{abstract}

Keywords: Placenta Accrete Spectrum (PAS), Feto Maternal Outcome, Positive Predictive Value

\section{Introduction}

Morbidly adherent placenta is a condition in which all or part of placenta is adherent to uterine wall because of myometrial invasion [1]. According to International Federation of Gynecology and Obstetric (FIGO) 2018 consensus the term "Placental Accreta spectrum (PAS)" refer to all three condition (accrete, increate, percreta) [1, 2]. Morbidly adherent placenta is important etiology maternal morbidity and mortality [3]. Placental accrete Spectrum (PAS) are commonly together with placenta previa is due to uterine damage (due to previous surgery, cesarean deliveries, curettage, myomectomy) poor handling allow the placenta to grow with absent Nitabuch Layer in myomectomy [4, 5].

Gielchnisky et al (2002) found the risk factors associated with PAS were cesarean section, advance maternal age, high gravidity, multiparity previous curettage, and placenta previa. Repeated cesarean section high parity and anterior low lying placental location were associated with severe outcomes in case of PAS [6].
Diagnosis of PAS are accomplished sonography with a sensitivity of $77-87 \%$, specificity of $96-98 \%$, positive predictive value of $65-$ $93 \%$ and a negative predictive value of $98 \%$ [7, 8]. Doppler ultasound in diagnosis of PAS is $93 \%$ and specificity is $71 \%$ [9]. Initial episode of bleeding has a incidence at about 34 weeks. It occurs in over $50 \%$ of cases before 36 weeks in only $2 \%$ after 40 weeks [10]. Obstetric hemorrhage is still considered to be one of the leading cause of maternal morbidity and mortality [11]. Incidence of serious congenital malformation is double with placenta previa [12]. Ananth et al (2000) examined the independent contribution of prematurity and fetal growth restriction to low birth weight babies among women with placenta previa [13].

The approach to management included various procedures, like obstetrical hystectomy, internal iliac arteries ligation, uterine ligation, sewing placental bed leaving placenta in situ, B Lynch suture, uterine packing, pelvic packing. wedge resection of uterus [14].

Prenatal diagnosis of PAS and planned delivery at experienced center are associated with significant reduction 
in maternal and fetal morbidity [15]. In an area of advanced imaging modalities antenatal detection of PAS regrettably remains variable, as many as $20 \%$ to $50 \%$ of cases of PAS escape antenatal diagnosis [16].

\section{Subject and Method}

It is a Cross sectional validation survey conducted at Department of Obstetrics and Gynecology Unit 1 Allied Hospital, Faisalabad for period of 6 month i.e. from January 2018 to June 2018. Sample size of 145 cases were calculated by using WHO sample size calculator for sensitivity specificity. WHO manual with confidence level 95\% confidence level and sensitivity $71 \%$, specificity $93 \%$, prevalence $82 \%$, absolute precision $10 \%$.

Pregnant women included in the study were those with age of 20-40 years, Primigravida to gravida 4 having single pregnancy on ultrasound with gestational age $>28$ weeks on ultrasound and diagnosed cases of placenta previa major degree on ultrasound.

Pregnant women having bleeding disorders (on investigations: decreased platelets count, deranged coagulation profile.), Placental abruption (on ultrasound). Informed consent was taken from the patient and data was kept anonymous for privacy.

145 patients who presented at the department of Gynecology Obstetrics, Allied hospital Faisalabad and who fulfilled the above criteria were counseled and explained the details of the study. Written Informed consent was taken regarding usage of personal information for purpose of study. All these patients were admitted in ward and their Doppler ultrasound studies were carried out to notice placenta accreta, increta, percreta. All these patients were followed till delivery. Their surgical findings for evidence of morbidly adherent placenta (acreta, increta, percreta) were noticed and compared with Doppler ultrasound report. All surgical procedures were performed by same surgical team. All this information were entered in predesigned pro-forma. Doppler ultrasound was carried out by senior radiologist in department of Radiology AHF.

Data was entered and analyzed by SPSS version 23 computer based software program. Mean and standard deviation were calculated for age and gestational age. Diagnostic accuracy, specificity, sensitivity, positive predictive and negative predictive value were calculated by using $2 \times 2$ table 1 and surgical findings were taken as gold standard. Qualitative variable like true positive will be presented as frequency and percentages.

Table 1. $2 \times 2$ Table for determination of sensitivity and specificity.

\begin{tabular}{lll}
\hline & Surgical evidence + & Surgical evidence - \\
\hline Doppler findings + & True positive (a) & False positive (b) \\
Doppler findings - & False negative (c) & False negative (d) \\
\hline
\end{tabular}

Sensitivity $=a / a+c \times 100$

Specificity $=d / b+d \times 100$

Positive predictive value $=\mathrm{a} / \mathrm{a}+\mathrm{b} \times 100$

Negative predictive value $=\mathrm{d} / \mathrm{c}+\mathrm{d} \times 100$

Diagnostic accuracy $=a+d / a+b+c+d \times 100$

\section{Results}

Distribution of cases by age shows, patients were between 20 - 40 years of age with mean age of $28.23 \pm 4.31$ years (Table 2). Distribution of cases by gestational age shows, patient's gestational age between 30-36 weeks. Mean gestational age was found to be $34.3 \pm 1.82$ weeks (Table 2). Out of 145 patients, patients were found to be married between from 1-15 years with mean married age of $3.52 \pm 2.39$ years (Table 3 ). Parity of patients were found to be between 1-5 with mean parity of $1.6 \pm 0.92$ (Table 3). Out of 145 patients 3D Doppler ultrasound showed 94 positive cases while per operative findings (Gold standard) showed 90 positive cases. Sensitivity rate was found to be $86.5 \%$, specificity was $90.24 \%$, positive predictive value (PPV) $95.7 \%$ and negative predictive value (NPV) 72.5\% (Tables 4-6).

Table 2. Distribution of cases by age.

\begin{tabular}{llllll}
\hline & N & Minimum & Maximum & Mean & Std. Deviation \\
\hline $\begin{array}{l}\text { AGE } \\
\text { gestational }\end{array}$ & 145 & 20 & 40 & 28.23 & 4.31 \\
age & 145 & 30 & 36 & 34.14 & 1.82 \\
\hline
\end{tabular}

Table 3. Distribution of cases by Marital Status and Parity.

\begin{tabular}{llllll}
\hline & N & Minimum & Maximum & Mean & Std. Deviation \\
\hline MARRIED & 145 & 1 & 15 & 3.52 & 2.39 \\
PARITY & 145 & 1 & 5 & 1.61 & .92 \\
\hline
\end{tabular}

Table 4. Comparison of Per-Operative finding vs 3D Doppler Ultrasound.

\begin{tabular}{llll}
\hline & \multicolumn{2}{l}{ Surgical Result } & \multirow{2}{*}{ Total } \\
& Positive & Negative & \\
\hline Doppler Ultrasound Positive & 90 & 4 & 94 \\
Negative & 14 & 37 & 51 \\
Total & 104 & 41 & 145 \\
\hline
\end{tabular}

$\mathrm{N}=145$.

Table 5. Sensitivity, Specificity and Diagnostic accuracy of 3D Doppler Ultrasound.

Sensitivity $=\frac{a}{a+c} * 100=\frac{90}{104} * 100=86.5 \%$
Specificity $=\frac{d}{b+d} * 100=\frac{37}{41} * 100=90.24 \%$
Diagnostic Accuracy $=\frac{T P+T N}{T P+F N+F P+T N} * 100=\frac{127}{145} * 100=87.6 \%$
$\mathrm{N}=145$.

Table 6. Positive predicative value and negative predictive value of $3 D$ Doppler Ultrasound.

$\mathrm{PPV}=\frac{a}{a+b} * 100=\frac{90}{94} * 100=95.7 \%$
$\mathrm{NPV}=\frac{d}{c+d} * 100=\frac{37}{51} * 100=72.5 \%$
$\mathrm{~N}=145$.

\section{Discussion}

Placenta accrete system (PAS) is one of the serious complications in obstetrics, it occurs when the placenta is abnormally adherent to the uterus. The most severe form of the condition is placenta percreta, in which the penetrates through the full thickness of the myometrium, through the 
serosa and may invade adjacent pelvic organs such as the bladder [17].

Identifying risk factors are important in emergency situations as awareness of clinical risk factors can aid in careful preoperative preparation and in counseling women with placenta previa regarding the likelihood of encountering morbidly adherent placenta with its attendant morbidity as recommended by ACOG and RCOG.

If limited to myometrium invasion, it is known as placenta increta. The etiology of morbidly adherent placenta has been thought to be due to absence of the spongious layer of deciduas and histology correspondingly shows the trophoblast invasion into the myometrium without intervening decidua. PAS can involve the entire placenta or fractions of it making the separation of placenta difficult at deli. An all too common end - result is massive hemorrhage and the need for caesarean hysterectomy [18].

The incidence of the placenta accreta is variable, and has been reported to be as high as one in 533 pregnancies, in a study by $\mathrm{Wu}$ et al. Risk factors of PAS include previous uterine scarring from caesarean sections, myomectomies, uterine curettages and infections. With increasing numbers of caesarean sections being now a days, it is postulated that the incidence of PAS would be on the rise.

A high index of suspicion is required for diagnosis and ultra sono graphic features suggestive of PAS must be sought in cases with risk factors [19].

Pelvic ultrasonography has been the most commonly used imaging modality for the diagnosed of PAS. LEVINE and the coworkers reported their experience with 19 women at risk of whom seven had MAP, of whom seven had morbidly adherent placenta. Ultrasonography accurately identified six of the seven women and correctly identified normal placentation in 11 of 12 cases [20].

In a larger series, Chou et al. [21], followed 80 women prospectively and of 16 considered to have ultrasound findings consistent with PAS, 14 had tissue evidence confirming the diagnosis of the remaining 64 studies interpreted as negative, placenta was adherent in three and the remainder was accurately diagnosed, resulting in a sensitivity of $82 \%$ and specificity of $96.8 \%$. The findings of these two studies suggest that ultrasonography has a primary role in screening women at risk of PAS [21].

As a screening tool to detect PAS, the prerequisite of each individual ultrasound criterion is a sensitivity to detect more true positives in women at risk. A low sensitivity but high specific test (e.g. disrupted bladder mucosa) would result in a number of undiagnosed cases, despite the high level of confidence in recognizing true negative cases [PAS]. Given the unique clinical management of PAS, the PPV and NPV of these diagnostic measures are as important as the sensitivity and specificity. Practically, the PPV reported for each criterion in this study indicates its reliability to correctly diagnose PAS; In other words, the confidence with which clinicians can proceed straight to hysterectomy without removing the placenta. In contrast, the NPV represents the precision of diagnosis of PAS, relating to the confidence with which clinicians can remove the placenta without concerns of severe bleeding.

According to the present study, 3D POWER Doppler ultrasonography can be used as a complementary technique for making or excluding the diagnosis of placenta accreta.

Finberg and Williamams, in their study found that gray scale ultrasound had a sensitivity of $93 \%$ and specificity of $79 \%$ [22].

The advent of Colour Doppler improved the diagnostic accuracy of conventional gray scale sonography [23-25].

Lerner and Colleagues reported a sensitivity and specificity of $100 \%$ and $94 \%$ respectively [23]

Levine and colleagues in their study found a sensitivity specificity of $86 \%$ and $92 \%$ respectively [24].

In present study, sensitivity was found to be $86.5 \%$, specificity $90.4 \%$, diagnostic accuracy $95 \%$, positive predictive value $95.7 \%$ and negative predictive value $72.5 \%$.

These findings are consistent with a study by Shih et al [26].

\section{Conclusion}

Placenta accrete system is an obstetric complication that is potentially ominous for the mother and that is currently developing the characteristics of an epidemic. This condition is one of the main causes of caesarean hysterectomy and fetomaternal morbidity and mortality. Diagnosis of this placenta accrete spectrum is based on two essential pillars: a high suspicion for disease based on the presence of risk factors, and both grey scale and colour Doppler ultrasound findings. In conclusion we believe that any persistent placenta previa, particularly in patients associated with prior cesarean section, must benefit from elaborate antenatal tranabdominal Doppler ultrasound studies to identify abnormal utero-placental vascular flow patterns. The extent and severity of hemodynamic changes of the uteroplacental circulation in placenta previa accreta must be taken into account. The identification of placenta accrete system has a positive impact on the peripatum clinical management of the affected pregnant ladies.

\section{Conflict of Interest}

All the authors do not have any possible conflicts of interest.

\section{Acknowledgements}

Author is grateful to the women participating in the study.

\section{References}

[1] Kean L. Antepartum haemorrhage. In: Luesly DM, Baker PN, Cardozo L, Drif J, editors. Obstetric and Gynecology evidence based text for MRCOG 1st ed. London: Arnold; 2004. p. 303. 
[2] Jauniax E, Chantraine F, Silver RM, Langhoff Roos J; FIGO placenta Accrta Diagnosis and Management Expert Consensus Panel. FIGO consensus guideline on placen ta accrete spectrum disorder: Epidimiology. Int J Gynaecol Obstet. 2018; 140 (3): 26573.

[3] Baker PN. Obstetrics by ten teacher $18^{\text {th }}$ ed. 338 london Arnold; 2006.

[4] Wu, S, Kocherginsky M, Hibbarad JU. Abnormal Placental: twenty years analysis. Am J Obstet Gynecol. 2005; 192 (5): 1458 61.

[5] Ananth CV, Svit DA, Luther ER. Maternal cigarette smoking as a risk factor for placental abruption,, Placenta Previa, and uterine bleeding Pregnancy. Am J Epidimiology. 1996; 144 (9): 881_9.

[6] Bahar A, Abusham A, Eskandar M, Sobande A, Alsunaidi M. Risk factors and pregnancy outcome in different types of placenta praevia. J Obstet Gynaecol Can 2009; 31: 126-31.

[7] Warshak CR. EsKander R, Hull AD, Sciosua AL, Mattrey RF, Benirschke Ket al. Accuracy of Ultrasonography and Magnetic resonance imaging in the diagnosis of placenta accrete. Obstet Gynaeccol 2006; 108 (3pt 1): 573_81.

[8] Comstock CH, Love JJ Jr, Bronsteen RA, Lee W, Vettraino IM, Huang RR et al. Sonographic detection of placenta accrete in the second and third trimester of pregnancy. Am J Obstet Gynecol. 2004; 190 (4): 1135_40.

[9] Biswas R, Sawhney H, Dass RS, Sarwan RK, Vasishta K. Histopathological study of placental bed biopsy in placenta praevia. Acta Obstet Gynecol Scand 1999; 78: 173-9.

[10] Robinson BK, Grobman WA. Effectiveness of timing strategies for delivery of individuals with placenta praevia and accreta. Obstet Gynecol 2010; 116: 835-42.

[11] Chou MM, Ke YM, Wu HC, Tsai CP, Ho ES, Ismail H, et al Temporary cross-clamping of the infrarenal abdominal aorta during caesarean hysterectomy to control operative blood loss in placenta praevia increta/percreta. Taiwan J Obstet Gynecol 2010; 49: 72-6.

[12] Oda N, Takeuchi K, Tanaka A, Maruo T. Obstetric risk factors associated with the development of periventricular leukomalacia in preterm infants born to mothers complicated by placenta praevia. Fetal Diagn Ther 2008; 24: 345-8.

[13] Harper LM, Odibo AC, Macones GA, Crane JP, Cahill AG. Effect of placenta praevia on fetal growth. Am J Obstet Gynecol 2010; 203: 330. el-S.

[14] Malik AM, Siddique S, Shah IA. Placenta praevia: a study to vitamin responsible factors. Prof Med J 2007; 14: 407-10.
[15] Hall T, Wax JR, Lucas FI, et al. Prenatal sonographic diagnosis of placenta accrete impact on maternal and neonatal outcome. J clin Ultasound. 2014; 42: 449 455.

[16] Bowman ZS, Eller AG, Kenndy AM, et al. Inter_observer variability of sonography for prediction of placenta accrete $\mathrm{J}$ ultrasound Med. 2014; 33: 2153_2158.

[17] Taipale P, Orden MR, Berg M, Manninen H, Alafuzoff I. Prenatal diagnosis of placenta accreta and percreta with ultrasonography, color Doppler, and magnetic resonance imaging. Obstet Gynecol 2004; 104: 537-40.

[18] Ruparelia BA, Chapman MG. Early low-lying placentae ultrasonic assessment, progress and outcome. Eur J Obstet Gynecol Reprod Biol 1985; 20: 209-13.

[19] McGahan JP, Philips HE, Reid MH. The anechoic retroplacental area: a pitfall in diagnosis of placental endometrial abnormalities during pregnancy. Radiology 1980; 134: $475-8$.

[20] Placenta accreta. ACOG Committee Opinion No. 266. American College of Obstetricians and Gynecologists. Obstet Gynecol 2002; 99: 169-170.

[21] Pelosi MA, 3rd, Pelosi MA. Modified cesarean hysterectomy for placenta previa percreta with bladder invasion: retrovesical lower uterine segment bypass. Obstet Gynecol 1999; 93 suppl: $830-3$.

[22] Finberg HJ, Williams JW. Placenta accrete; prospective sonographic diagnosis in patients with placenta previa and prior caesarean section. J Ultrasound Med. 1992; 11: 333 _43.

[23] Lerner JP, Dean S, Timor Tritsch IE. Characterazation of Placenta acccreta using transvaginal sonography and colour Doppler imaging. Uultrasound obstet Gynaecol. 1995; 5: 198_201.

[24] Levine D, Huulka CA, Ludmir J, Li W, Edelman RR. Placenta acccreta: evaluation with colour Doppler US, power Doppler US, and MR imaging. Radiology. 1997; 205 (3): 773_6.

[25] Chou MM, Ho ES, Lee YH. Prenatal diagnosis of placenta previa accrete by transabdominal colour Doppler ultrasound. Ultrasound Obstet Gynecol. 2000; 15: $28 \_35$.

[26] Shih JC, Palacios Jaraquemada JM, Su YN, Shyu MK, Lin $\mathrm{CH}$, Lin SY, et al. Role of three- dimensional power Doppler in the antenatal diagnosis of placenta accreta: comparison with gray-scale and color Doppler techniques. Ultrasound Obstet Gynecol. 2009; 33: 193-203. 